\title{
High School Grade, English language proficiency and computer skills as predictors of performance over five years of dental college: analysis and interpretation
}

\begin{abstract}
Colleges of Dentistry are faced with the annual task of selecting the dental applicants most likely to excel out of an extremely competitive applicant pool. The aim of this study was to investigate variables that influence student's performance in a retrospective sample including all undergraduate students who entered in to Ajman dental college, between 1989 and $2010(n=1141)$. Demographic and educational variables were used to predict performance in the overall curriculum and course groups. Standard ANOVA tests were used to examine the relationship between multiple indicators of admission criteria and dental college performance for the sixth cohort at the College of Dentistry, Ajman University. The admission criteria included the high school grade, English language and computer skills. Measures of dental college performance were the yearly and final dental college GPA/AGPA (Grade- Point- Average/Accumulative- Grade- Point- Average) and academic progress through the dental program. In general, most admission criteria were good indicators of dental college performance. Multivariate analyses indicated that students with higher grades in high school and English language and computer skill scores were more likely to achieve higher AGPA scores. The computer skill GPA and high school score were the most consistent determinants of dental college AGPA. Students with lower high school grade, computer and English language skill were more likely to remediate, to repeat an academic year, or to be dismissed from college.
\end{abstract}

Keywords: admission criteria, dental college, dental college performance, english language skill, high school grade
Volume 8 Issue 7 - 2017

\author{
Mohamed A Jaber,' Salem Abufanas, ${ }^{2}$ \\ Mohamed Dejedi ${ }^{3}$ \\ 'Department of Oral Surgery, Hamdan Bin Mohamed College of \\ Dental Medicine, UAE \\ ${ }^{2}$ College of Dentistry, Ajman University, UAE \\ ${ }^{3}$ Canadian University, UAE
}

\begin{abstract}
Correspondence: Mohamed A Jaber, Department of Oral Surgery, Hamdan Bin Mohamed College of Dental Medicine, Dubai Healthcare City, Dubai, UAE,
\end{abstract}

Email mjaber4@hotmail.com, Mohamed.jaber@mbru.ac.ae

Received: November 06, 2017 | Published: December II, 2017

\section{Introduction}

The process of selecting the most appropriate and best dental applicants out of an extremely competitive applicant pool is a challenge regularly encountered by dental colleges. Colleges of Dentistry are faced with the annual task of selecting the dental applicants most likely to excel out of an extremely competitive applicant pool. Traditionally, the decisions to accept or reject candidates are based upon recommendation letters, high school performance as a measure of academic achievement, psychomotor skills, perceptual abilities, and an interview. ${ }^{1-4}$ Dental students are required to acquire considerable amounts of knowledge in relatively short periods of time. Individuals with high cognitive ability should have more success in academic components of their programs, as suggested by previous studies. ${ }^{3-5}$ It was reported that dental students who are admitted based on Aptitude Test scores do significantly better than those accepted through other factors and the Aptitude Test predicts academic performance of students during the first two years of dental training also correlate with grades in theory courses in dental college. ${ }^{6}$ Thus the aim of this study was to investigate variables that influence student's performance in particular the correlation between high school scores, English language proficiency and computer skills on the academic progression and overall performance in the dental program.

\section{Material and methods}

The study population consisted of 1141 students who were enrolled in the college of dentistry, Ajman University (AU) from 1989 through 2010. Admission criteria included High school score, English language proficiency test score and computer skill score. Students' academic progress during dental college was measured by yearly GPA, and final (Accumulative) GPA. Yearly and final GPAs were calculated on a 4.0 points scale and were weighted appropriately for credit hours. The authors obtained information about yearly and final GPA, high school grades, English language course scores, computer skill scores and attrition rates from the Office of Admission and Registration Ajman University. After approval of the research protocol by AU Ethical Committee, demographic features, preadmission credentials, and academic data were retrieved by the University Registrar's Office. Retrieved data for this study included students' gender, type of high school (private or public), high school grade and rank of candidate's performance in the admission interview. Academic data comprised student's academic performance. In UAE, performance of dental students is provided by the overall cumulative grade point average. The whole sample was segmented into a predefined number of clusters according to Student's grades in high school, so that students categorized into a 3-cluster: higher; 90 and above, moderate; 85-90 and lower grade less than 85. Statistical 
differences among clusters were investigated using chi-square test and one-way ANOVA. Paired-samples t test was used to compare performance of different course groups. Stepwise multiple regression analysis was used to test the influence of independent variables on the overall student's performance. Significance level was set at $\mathrm{p}<0.05$. SPSS 20.0 for Windows was used for statistical analysis.

\section{Results}

The Study population included 1141 students, $78.3 \%$ females and $21.7 \%$ males. Mean age was 19.62 years $(\mathrm{SD}=2.07)$ at the time of dental school admission and 23.00 years $(\mathrm{SD}=2.09)$ at the time of graduation.

Table I Distribution of students according to high school scores

\section{Analysis of the effect of high school scores on the academic warnings}

The statistics of the distribution of the students enrolled according to the three categories of the high school scores are given in Table 1. Table 2 indicates that the percentage of warned students decreases in relation to an increased school score for both male \& female students. It indicates clearly that the quasi-majority $(93.4 \%)$ of students with school scores greater than $90 \%$ did not encounter academic problems during their enrolment whereas about a quarter $(23.2 \%)$ of students with a score in the range of $85-90 \%$ did encounter academic problems. However, $33.8 \%$ of students with a score less than $85 \%$ are warned students. We also note that the percentage of warned male students is higher than that of female students for each of the three groups.

\begin{tabular}{llll}
\hline Gender & Female & Male & Male and Female \\
\hline Group & & & \\
\hline Less than $85 \%$ & 235 & 114 & $349(30.5 \%)$ \\
$85 \%-90 \%$ & 279 & 101 & $380(33.4 \%)$ \\
More than $90 \%$ & 380 & 32 & $412(36.1 \%)$ \\
Total & 894 & 247 & $1141 *(100 \%)$ \\
\hline
\end{tabular}

Table 2 Percentage of warned and non-warned students for each group

\begin{tabular}{lllllll}
\hline Gender & Female & \multicolumn{2}{c}{ Male } & \multicolumn{2}{c}{ Male and Female } \\
Group & Not Warned & warned & Not Warned & Warned & Not Warned & Warned \\
\hline Less than $85 \%$ & $71.50 \%$ & $28.50 \%$ & $55.30 \%$ & $44.70 \%$ & $66.20 \%$ & $33.80 \%$ \\
$85 \%-90 \%$ & $78.10 \%$ & $21.90 \%$ & $73.30 \%$ & $26.70 \%$ & $76.80 \%$ & $23.20 \%$ \\
More than 90\% & $94.50 \%$ & $5.50 \%$ & $81.20 \%$ & $18.80 \%$ & $93.40 \%$ & $6.60 \%$ \\
\hline
\end{tabular}

\section{Analysis of the effect of secondary school scores on the overall performance}

In this section, we present the results of statistical analyses that were conducted to investigate the effect of the high school scores on the overall performance of students as measured by the AGPA variable. The analysis was conducted using ANOVA method for comparing the averages of the overall performance of students for the three groups mentioned in Table 1 above. The outputs of the ANOVA analysis for both female and male students, shown in Table $3 \& 4$ indicate that there is a significant difference between the averages of the AGPA variable for the three groups since the P- value is 0.000 . Furthermore, the $95 \%$ confidence intervals of the means of the AGPA variable for the three groups indicate that the AGPA increases, on average, as the school score increases. However, the pattern of the location of the confidence intervals differs for Female and Male students. For instance, we notice that the $95 \%$ confidence intervals of the mean of male AGPA overlap for the two groups, $60-70 \%$ and more than $70 \%$, indicating that a score of less than $60 \%$ had a different effect on the overall performance of male students. This is due to the fact that the overall performance of male students is much lower than that of female students for the third group (students with score more than $70 \%)$.
Table 3 One-way analysis of variance of AGPA for female students

\begin{tabular}{lcccccc}
\hline \multicolumn{4}{l}{ Analysis of Variance } & & & \\
Source & DF & SS & MS & F & P \\
Factor & 2 & 41.784 & 20.892 & 70.92 & 0 \\
Error & 891 & 262.463 & 0.295 & & \\
Total & 893 & 304.248 & &
\end{tabular}

Individual 95\% Cls for Mean Based on Pooled St Dev

$\begin{array}{llll}\text { Level } & \text { N } & \text { Mean } & \text { St Dev } \\ \text { Agpa }<60 & 235 & 2.228 & 0.5576 \\ \text { Agpa-60-70 } & 279 & 2.3732 & 0.5491 \\ \text { Agpa }>=70 & 380 & 2.7298 & 0.5286\end{array}$

Pooled St Dev=0.5427 2.20 2.40 2.60 2.80 
Table 4 One-way analysis of variance of AGPA variable for male students

\begin{tabular}{lcccccc}
\hline \multicolumn{4}{l}{ Analysis of Variance } \\
\hline Source & DF & SS & MS & F & P \\
Factor & 2 & 5.184 & 2.592 & 10.69 & 0 \\
Error & 244 & 59.167 & 0.242 & & \\
Total & 246 & 64.352 & & & & \\
& & & & & &
\end{tabular}

ndividual 95\% Cls for Mean based on Pooled st Dev

$\begin{array}{lccc}\text { Level } & \mathbf{N} & \text { Mean } & \text { st Dev } \\ \text { Agpa }<60 & \mathrm{I} 14 & 2.0265 & 0.448 \\ \text { agpa60-70 } & 101 & 2.2746 & 0.5295 \\ \text { Agpa }>7 & 32 & 2.4034 & 0.5222\end{array}$

Pooled St Dev=0.5427 2.20 2.40 2.60 2.80

Analysis of the effect of students computer skills on the overall performance

To investigate whether there is dependence between the overall performance and computer skills gained by students in the course of Information Technology Fundamentals (0310100), we conducted a contingency table analysis of the AGPA and the Mark obtained in the first registration in the computer skills course by students that were enrolled in the program.

We categorized the Mark variable into five categories: F, D, C, B and A such that:

i. $\quad \mathrm{F}$ if the Mark is below 60

ii. $\mathrm{D}$ if the Mark is between 60 and less than 70

iii. $\mathrm{C}$ if the Mark is between 70 and less than 80

iv. $\quad$ B if the Mark is between 80 and less than 90

A if the Mark is 90 or above

Whereas the AGPA Variable was categorized into 4 categories:

1. Weak: if the AGPA is less than 2

2. Satisfactory: if the AGPA is between 2 and less than 2.5

3. Good: if the AGPA is between 2.5 and less than 3

4. Very Good: if the AGPA is 3

Table 5, given below, gives the observed frequency for each combination of the two variables, and the expected frequency under the hypothesis that there is independence between the two variables. It indicates that $61 \%$ of weak students obtained the grade of $\mathrm{F}$ or D in the course 310100 . This percentage is $34 \%, 18 \%$, and $2 \%$ for the satisfactory, Good and Very Good overall performance respectively. This indicates that computer skills have an effect on the overall performance of students. The application of the formal Chi- square test, for testing independence of the overall performance on computer skills, gives a $\mathrm{P}-$ value equal to 0.000 .
Table 5 Observed and expected frequencies using AGPA and course Mark.

\begin{tabular}{|c|c|c|c|c|c|c|}
\hline$\frac{\text { AGP }}{\text { Mark }}$ & & -Weak & Satisfactory & Good & Very Good & Total \\
\hline \multirow{2}{*}{$F$} & Observed & 26 & 10 & 6 & 0 & 42 \\
\hline & Expected & 7.65 & 15.43 & 11.96 & 6.96 & 42 \\
\hline \multirow{2}{*}{ D } & Observed & 82 & 112 & 43 & 3 & 240 \\
\hline & Expected & 43.73 & 88.2 & 68.32 & 39.75 & 240 \\
\hline \multirow{2}{*}{ C } & Observed & 51 & 143 & 107 & 35 & 336 \\
\hline & Expected & 61.22 & 123.48 & 95.65 & 55.65 & 336 \\
\hline \multirow{2}{*}{ B } & Observed & 15 & 78 & 95 & 80 & 268 \\
\hline & Expected & 48.83 & 98.49 & 76.29 & 44.39 & 268 \\
\hline \multirow{2}{*}{ A } & Observed & 2 & 12 & 24 & 42 & 80 \\
\hline & Expected & 14.58 & 29.4 & 22.77 & 13.25 & 80 \\
\hline \multirow[t]{2}{*}{ Total } & Observed & 176 & 355 & 275 & 160 & 966 \\
\hline & Expected & 176 & 355 & 275 & 160 & 966 \\
\hline
\end{tabular}

Analysis of the effect of English skills on the overall performance

Table 6 gives the observed and expected frequency for each combination of the categories of the AGPA variable and the grade in the first registration in the English course entitled English I. We notice that $88 \%$ of weak students (AGPA less than 2) obtained $\mathrm{F}$ or $\mathrm{D}$ in this course. This percentage is reduced to $64 \%, 43 \%$, and $19 \%$ for students with Satisfactory, Good, and Very Good overall performance, respectively. Furthermore, the Chi-square test for testing independence indicated that independence between the two variables is rejected since the $\mathrm{P}-$ value was found equal to 0.000 .

Table 6 Observed and expected frequencies using AGPA and English course score

\begin{tabular}{lllllll}
\hline \multicolumn{2}{l}{ AGPA } & Weak & Satisfactory & Good & Very Good & Total \\
\multicolumn{1}{l}{ Mark } & & & & & \\
\hline F & Observed & 35 & 34 & 6 & I & 76 \\
& Expected & 15.24 & 27.47 & 22.2 & 11.1 & 76 \\
D & Observed & 107 & 152 & 96 & 22 & 377 \\
& Expected & 75.59 & 136.24 & 110.11 & 55.06 & 377 \\
C & Observed & 14 & 83 & 87 & 34 & 218 \\
& Expected & 43.71 & 78.78 & 63.67 & 31.84 & 218 \\
B & Observed & 6 & 20 & 41 & 42 & 109 \\
& Expected & 21.85 & 39.39 & 31.84 & 15.92 & 109 \\
A & Observed & 0 & 3 & 6 & 19 & 28 \\
& Expected & 5.61 & 10.12 & 8.18 & 4.09 & 28 \\
Total & Observed & 162 & 292 & 236 & 118 & 808 \\
& Expected & 162 & 292 & 236 & 118 & 808 \\
\hline
\end{tabular}

Citation: Jaber MA, Abufanas S, Dejedi M. High School Grade, English language proficiency and computer skills as predictors of performance over five years of dental college: analysis and interpretation. J Dent Health Oral Disord Ther. 2017;8(7):670-674. DOI: 10.15406/jdhodt.20I7.08.003 I3 


\section{Discussion}

College of dentistry, Ajman University is a private dental college has a 5-year curriculum and offers 150 places to new incoming students annually. In the first 2 years of the undergraduate program, courses predominantly basic and non- clinical courses, while in the subsequent years students have clinical courses. UAE universities accept students directly from high school. Admission to dental school is a very competitive process due to the high proportion of applicants per place. Admission depends on the Sudent's grade in the high school, English language proficiency and interview. This study demonstrates that dental students with higher grades in high school and English language and computer skill courses were more likely to achieve higher AGPA scores. The computer skill GPA and high school score were the most consistent determinants of dental college overall AGPA, this is consistent with the findings of the previous studies..$^{3-9}$ The majority of students with high school scores greater than $90 \%$ did not encounter academic problems during their enrolment whereas about a quarter $(23.2 \%)$ of students with a score in the range of $85-90 \%$ did encounter academic problems. However, $33.8 \%$ of students with a score less than $85 \%$ are warned students. We also noted that the percentage of warned students is higher than that of female students for each of the three groups. Previous studies of impact of gender on student performance found that men outperformance women, attributing possible reasons as: women's lowest sense of self- esteem, stereotype threat, differential speeds, aversion to risk taking, test bias, fear of success, test anxiety, and certain other personal characteristics. ${ }^{10}$ Fields et al. ${ }^{11}$ investigated the impact of gender in student's performance among dental students and found that there were no significant differences. Authors related this result to no presence of true differences or power of the sample to detect small differences. Kramer $\mathrm{GA}^{5}$ concluded that students who withdrew from dental school in poor academic standing had lesser academic qualifications than did those who withdrew in good academic standing or who remained in dental school. This study demonstrates that the admission criteria showed several significant associations with programmatic status and we were able to identify and evaluate differences between those students who graduated without difficulty, those who graduated with difficulty, those who were dismissed or withdrew in poor academic standing, and those who withdrew in good academic standing. This result might seem to restate that students who are better trained in computer science and have good command of the English language will be better prepared to make use of a curriculum that is steeped in the basic and clinical sciences. Some authors' attempts to demonstrate whether a strong correlation exists between the dental school admission interview score and dental school performance outcomes and have found no correlation and concluded that the admission interview score does not consistently predict academic success. ${ }^{5-14}$ Other studies have found a weak correlation and concluded that the interview score may be one factor among many that indicates the likelihood of success during the clinical years of dental school, or that the interview score may enable educators to better anticipate any academic problems that may arise as a student progresses through the curriculum..$^{2-15}$ The marked differences that separate these studies may be readily attributed, however, to differences in the interviewing process as implemented by different schools. If dental schools are better able to identify students at risk, they may take active measures to prevent failure rather than rely on passive remedial measures after the fact. Our finding of firstyear dental school GPA being a significant predictor for the GPA at graduation is consistent with investigators who have found that early assessments within an educational program are often strong predictors of later performing students. In a retrospective study of 352 medical students, Croen et al. ${ }^{16}$ found marginal performance on exams early in the first year were more predictive in identifying students at risk academically than GPA. Croen et al. ${ }^{16}$ attributed this finding to the similar environment of assessments and outcome measurements, which they felt afforded higher predictive validity. The most significant finding from this study is the admission decisions based on measures related to cognitive abilities and academic performance in undergraduate work will for the most part predict academic success in dental school Smithers et al. ${ }^{17}$

The purpose of the admissions committee is to select the best candidates from a qualified applicant pool. If these candidates were able to demonstrate that they would be able to graduate from dental college within the recommended time then the task of the admissions committee would be simplified. Prospective studies that would validate a model of selected admission criteria in predicting academic difficulties including success in clinical practice in the dental college curriculum are warranted. That would hopefully allow admission decisions to be based not only on projections of performance in the classroom, but also on the potential for success in the clinical training and beyond.

\section{Conclusions and recommendation}

The analysis indicates that high school scores have an effect on the overall performance of students; therefore, it is recommended that high school scores of $80 \%$ and more be observed as a variable in admission requirement with emphasis on competitive base. The analysis indicated that AGPA depends significantly on the scores obtained in the Information Technology Course. Therefore, it is recommended that newly admitted students are required to take this course during the first semestehe analysis indicated that AGPA depends significantly on the scores obtained in the English language proficiency course. Therefore, it is recommended that students should pass an entry English test prior to admission to the dental college.

\section{Funding}

None.

\section{Acknowledgments}

None.

\section{Conflicts of interest}

None.

\section{References}

1. Boyd MA, Teteruck WR, Thompson GW. Interpretation and use of the Dental Admission and Aptitude Tests. J Dent Educ. 1987;44(5):275-278.

2. Oudshoorn WC. The utility of the Canadian DAT perceptual ability and carving dexterity scores as predictors of psychomotor performance in the first-year operative dentistry. J Dent Educ. 2003;67(11):1201-1208.

3. Gray SA, Deem LP, Straja SR. Are traditional cognitive tests useful in predicting clinical success? J Dent Educ. 2002;66(11):1241-1245.

4. Sandow PL, Jones AC, Peek CW, et al. Correlation of admission criteria with dental school performance and attrition. J Dent Educ. 2002;66(3):385-392. 
5. Kramer GA. Predictive validity of the Dental Admission Test. $J$ Dent Educ. 1986;50(9):526-531.

6. Dworkin SF. Dental aptitude test as predictors of performance over four years of dental school: analysis and interpretation. $J$ Dent Educ. 1970;34(1):28-38.

7. Schmidt FL, Hunter JE. The validity and utility of selection methods in personnel psychology: practical and theoretical implications of 85 years of research findings. J Psychol Bull. 1998;124(2):262-274.

8. Jones AC, Courts FJ, Sandow PL, et al. Type Indicator and dental school performance. J Dent Educ. 1997;61(12):928-933.

9. Reddick GH, Macfarlane TV. An analysis of an admissions system: can performance in the first year of the dental course be predicted? $\mathrm{Br}$ Dent J. 1998;186: 138-142.

10. Park SE, Da Silva JD, Barnes Jl. Predicting dental school performance based on prior dental experience and exposure. Eur J Dent Educ. 2010;14(1):1-6.

11. Fields HW, Fields AM, Beck FM . The impact of gender on high-stakes dental evaluations. J Dent Educ. 2003;67(6):654-660.
12. Edwards JC, Johnson EK, Molider JB. The interview in the admission process. J vet Med Educ. 1990;65(3):167-176.

13. Wiesner WH, Cronshaw SF A. meta-analytic investigation of the impact of interview format and degree of structure on the validity of the employment interview. Journal of Occupational Psychology. 1988;61(4):275-290.

14. Wright PM, Lichtenfels PA, Pursell ED. The structured interview: additional studies and a meta-analysis. J Occupational Psychology. 1989;62(3):191-199.

15. Graham JW, Boyd MA A structured interview for dental school admissions. J Dent Educ. 1982;46(2):78-82.

16. Croen LG, Reichgott M, Spencer RK A performance- based method for early identification of medical students at risk of developing academic problems. Acad Med. 1991;66(8):486-488.

17. Smithers S, Catano VM, Cunningham DP. What Predicts Performance in Canadian Dental Schools? J Dent Edu. 2004;68(6):598-613. 